\title{
Spruce-A Intelligent Surveillance Device for Monitoring of Dustbins using Image Processing and Raspberry PI
}

\author{
Navjot Rathour, Anita Gehlot, Rajesh Singh
}

\begin{abstract}
In the current scenario, most recurrently we find that the Dust bins kept at various places mainly at public places in the cities are swarming because of elevation in garbage every day. Mainly it creates filthy and unhealthy conditions for humanity which leads to spreading of lethal diseases. In addition to that, anyone can hide eruptive material under this sort of mess and that can lead to loss of lives. To avoid these wretched situations a Waste Monitoring System using Internet of Things which is named as SPRUCE is proposed. This system is not designed for single dustbin rather multiple dustbins that are kept at different location in cities or campus; these garbage bins are designed with cheap device that helps in monitoring the level of trash inside the trash bins. In addition to that, SPRUCE can click the image and send it on server. This feature can help the monitoring authorities to identify as well locate them for further action. Moreover, these clicked images can help to identify the updated status of bins even by sitting at a dedicated place only and quickly a corrective action can be made to clean the dustbins.
\end{abstract}

\section{INTRODUCTION}

In imperative rundown, it is observed that the trash bins are squiring over as these trash bins are kept in the cities for waste collection. The main reason behind the overflow is upsurge of waste every day. Due to which the surroundings get contaminated and feeble situations are created. This makes the spreading of ailments and human infirmity [1]. To evade these conditions a smart garbage management system has been proposed that can measure the level of trash inside bin which can be recognized online [2]. A web page used for monitoring the level of garbage inside the junk bins online, which can act as base for any future activity against the culprits [3]. Such systems are helpful for attracting the alertness of corresponding authorities, which in turn help the respective authority to act against offenders and support to maintain the hygienic conditions across city [4]. Trash management is one of the serious issues that must be fathomed in the case of developed or growing nation. To avoid hazardous situation which can harm mankind or surrounding the status of the trash bins need to be realized well ahead of time [5]. The major reason behind the development of smart garbage management system is to develop a system that can be monitored centrally with the help of IoT that can lead to instant cleaning of bins [6]. To raise the awareness amongst people government has already started various movements and large number of people are making all possible efforts to keep the environment and surroundings clean and hygienic. A system is proposed with a sensor mounted on the canister to detect the level of garbage and at a particular point when the trash will achieve the most extreme dimension, a notice will be sent to the Gmail and activities to discharge the canister. This framework will help in cleaning the city in more better way [7]. Collection and management of garbage is one of the most challenging and exhaustive process. Mainly for an establishing economy, where a substantial assortment of products extending from vehicles to metal and equipment end up in deficiently oversaw and uncontrolled dumpsites, spreading infections and expanding contamination [8]. The main purpose of this device is to minimise the human efforts and maximise the enhancements for the smart cities. As these smart bins will be squashed on regular intervals, so trash will be easy to manage if conventional garbage bins will be replaced by these smart bins. Such replacement can be proved beneficial for society [9]. IoT (Internet of Things) is one of the most effective element that can manage the solid waste. Wide range of literature is available on smart waste management system using IoT [10]. The world is continually being contaminated by not just the arrival of hurtful Green-house gases yet additionally by the ill-advised transfer of Trash, prompting ecological contamination which makes unhygienic living conditions Smart Trash Bin is an Innovative, Life-changing undertaking which will help in making nature contamination free. Often the refuse jars in work environments become full and start to flood, in this manner making the working environment rotten, since the specialists don't land on time to gather the junk [11]. This Smart dustbin venture proceeds onward its very own when called and gathers the waste, accordingly improving the work process, however not just that, it's shrewd as well. In this way, making it an increasingly savvy and effective [12].
Revised Version Manuscript Received on August 19, 2019.

NavjotRathour, Lovely Professional University, Phagwara Punjab, India.(email: er.rathour@gmail.com)

Anita Gehlot, Lovely Professional University, Phagwara Punjab, India. (email: eranita5@gmail.com)

Rajesh Singh, Lovely Professional University, Phagwara Punjab, India (email: srajssssece@gmail.com) 


\section{II.BLOCK DIAGRAM}

The following components are required to design the system like Raspberry pi Board, Arduino Board, Servo motor, Camera Module, PIR Sensors, Ultrasonic sensor, Connecting wires, Power Supply. The description of the components is as follows:

\section{Raspberry Pi Board-}

The Raspberry Pi is cheap and compact sized computer. USB Keyboard, Mouse and monitor can be connected to it that will make it perfect computer. It is easy to use and handy device that can be used by people of all age groups. It works on Linux and languages like Python can be easily learn for making any sort of projects. Specially designed modules like $\mathrm{Pi}-\mathrm{Cam}$ and $\mathrm{Pi}$-screen make it versatile.

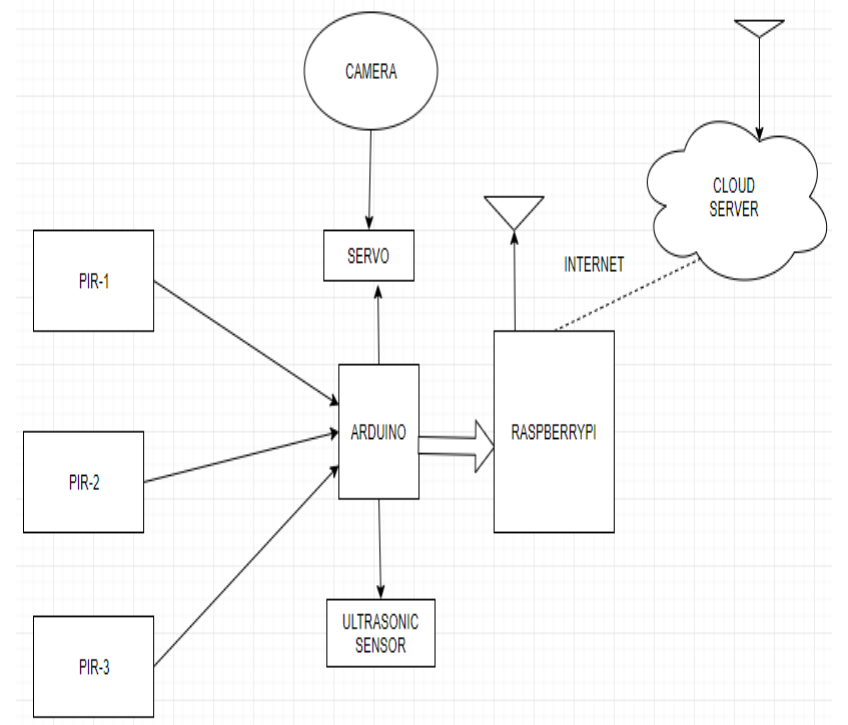

Fig1. Block diagram of the system

\section{ARDUINO-}

An open-source gadget which is simple to use and very easy to program.Arduino boards can read data from any analog or digital sensors and can take inputs from them. After taking inputs that data can be converted into digital data and can be sent to any output device for activation of motor, publishing something online, plotting data loggers, turning on and off LEDs etc. The Arduino board can be guided and instructions can be given to the board via programming language. The arduino should be wired with a system for programming purpose and this can be done with the help of Arduino Software (IDE).

\section{PIR sensor-}

PIR is known as passive infrared sensor. This sensor mainly detects the infrared light emitted by the human beings or animals that comes mainly in the range of PIR sensor. Such sensors are very helpful in the detection of intruders depending on various surveillance applications.

\section{Ultrasonic sensor-}

Ultrasonic sensors mainly work on the ultrasonic waves so they are actually the sensors which work on acoustic signals. These sensors are classified in three different categories i.e transmitters, receivers and transceivers. The main work of transmitter is to convert the electrical signal into acoustic signal on the other hand receivers convert the ultrasonic signal to electrical signal, while transceivers can do both operations of transmitter and receiver as well. These sensors are mainly used to detect the exact location of obstacle.

\section{Servo motor-}

A revolving engine that is having the capabilities of speeding up and speeding down, revolved at a precise position and can provide a particular angle for rotation is known as servo motor. It makes utilization of a normal engine and sets it with a sensor for position feedback. The controller is the most advanced piece of the servo engine, as it is explicitly intended for the reason.

\section{III.HARDWARE DEVELOPMENT}

The hardware connections of the system are shown in fig2, in which Pi camera is connected to the camera module of the Raspberry-Pi board. Arduino board is connected via USB 0 of Raspberry Pi. PIR sensor is connected to the Analog pin 4 of Arduino. Servo motor is connected to pin 6 and ultrasonic sensor is connected to pin 2 of Arduino. The main purpose of camera module is to identify ad detect the human face. Ultrasonic sensor will help to detect the level of garbage inside the bin and inform the authorities by sending email or message via cloud server. PIR sensor will detect the human being within defined range around bin and will turn on the camera module for capturing the human faces. Servo Motor is used to provide rotation in 360 degrees. 


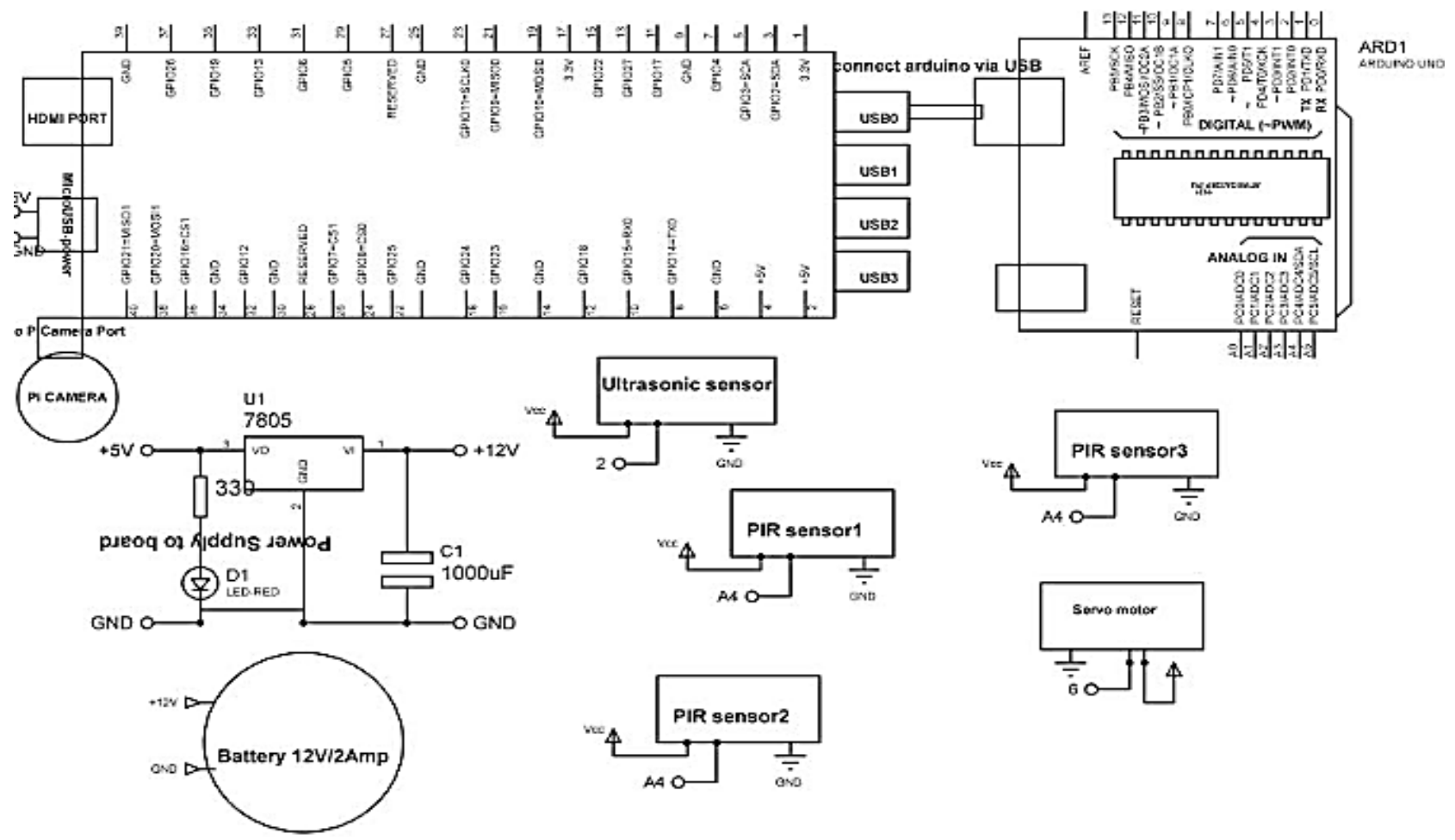

Fig2. Circuit diagram of the system

\section{IV.WORK FLOW AND SOFTWARE DEVELOPMENT}

The algorithmic flow of the system is explained in fig 3 and fig4. The trash management is explained in figure 9 which shows that after reaching a particular level when dustbin is full with trash, a message will be sent to central control room. The control room will further inform the cleaning staff and send the vehicle for the collection of trash. After cleaning the status of dustbin will be updated. The other important part of the proposed system is the detection of human being near trash bin and capture the face of the person for future action. Fig5 shows the flow to detect the human facial images and after detection the images will be stored on cloud. The camera module will be used to capture the human facial images only after detecting the presence human being with the help of PIR sensor. Figure 11 shows the complete workflow of SPRUCE system.

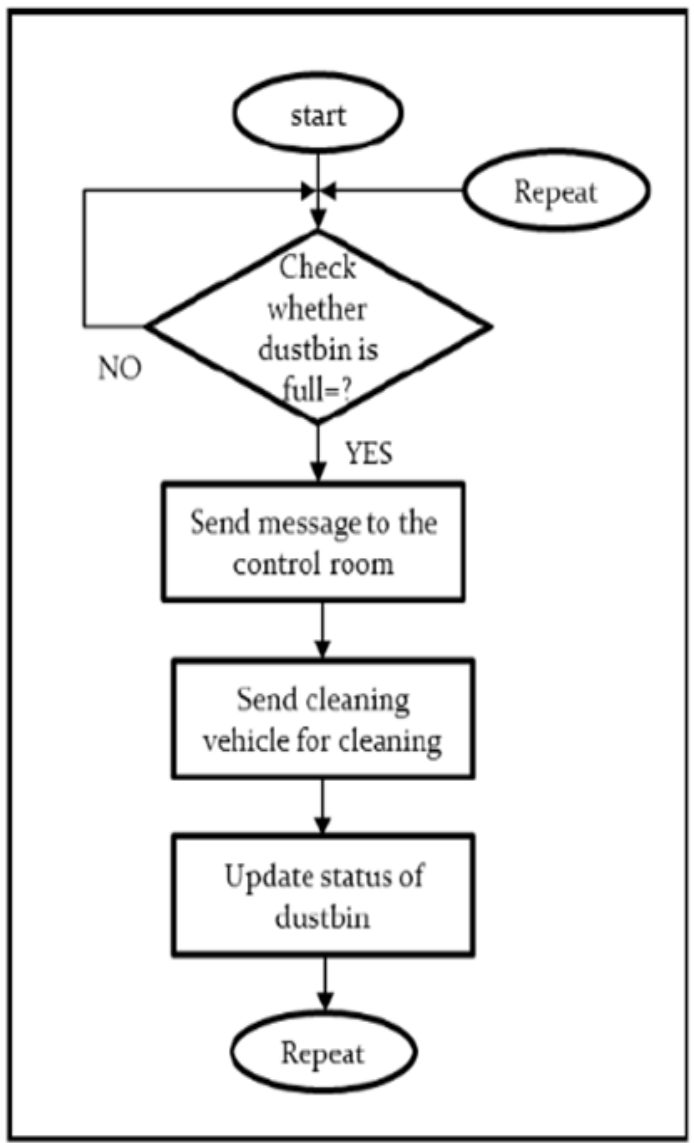

Fig3. Flow chart of the system

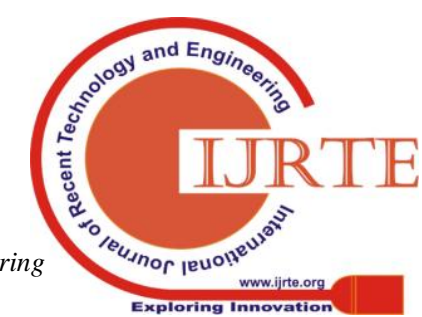




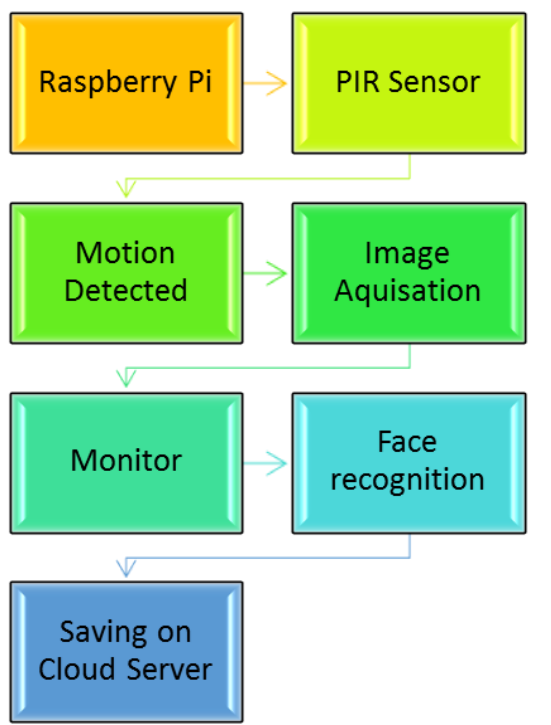

Fig4.Proposed system for detecting human faces.

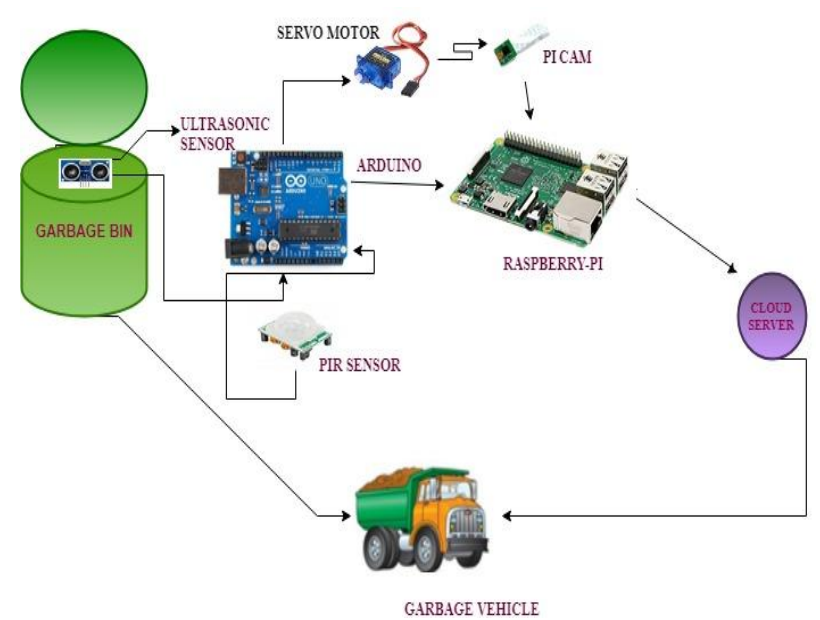

Fig5. SPRUCE System workflow

For testing the camera we will import NumPy library in OpenCV 2

importnumpy as np

import cv2

For Capturing the video of desired resolution we can give capture command

cap $=$ cv2.VideoCapture $(0)$

cap.set(3,640) \# set Width

cap.set $(4,480)$ \# set Height

For displaying the captured frame imshow command can be used

cv2.imshow('frame', frame)

cv2.imshow('gray', gray)

Face detection process is basically classified in three tightly coupled steps

Face Recognition: Viola Jones algorithm has been used to detect the facial images.

Feature Extraction: After the successful detection of face, the selection of feature is one of the most essential steps. Various feature extraction techniques available out of those Haar Like feature is used to extract various features.

Classification: Last step of automatic facial expression analysis sys-tem is classification. SVMs (Support Vector Machines) and Adaboost are the most widely used classifier and hence used.

\section{V.RESULT AND DISCUSSION}

The proposed system is smart trash management and monitoring system that uses Ultrasonic sensor, Arduino Uno, PIR sensor and Raspberry pi. This system assures the cleaning of dustbins quickly when the trash level is at maximum defined limit. Not only that it captures the facial image of the person also that will help to identify the person by matching it with database for future action. If the dustbin isn't cleaned in explicit time, at that point the record is sent to the Sweeper or more recognizable expert who can make proper move against the concerned temporary worker. This system additionally screens the phony reports and thus can minimise the defilement in the general administration framework. This diminishes the complete number of rounds of garbage accumulation vehicle and consequently decreases the general use related with the waste gathering. It eventually improves the cleanliness. In this manner, the Automatic Garbage Fill Alerting framework makes the trash collection progressively proficient. View of the outcome in terms of live video streaming of dustbin Video and graph read by ultrasonic sensor to measure the level in cm shown in Fig6.
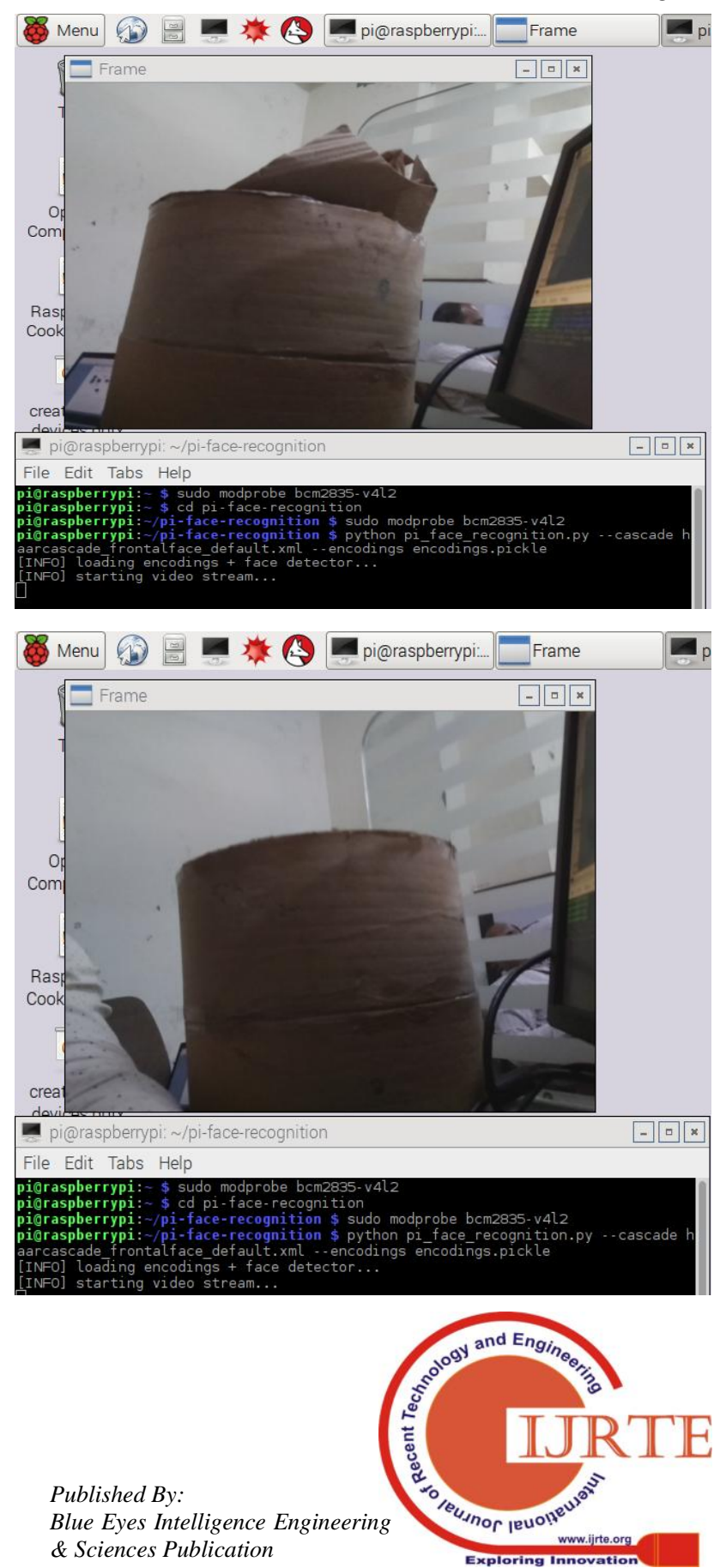


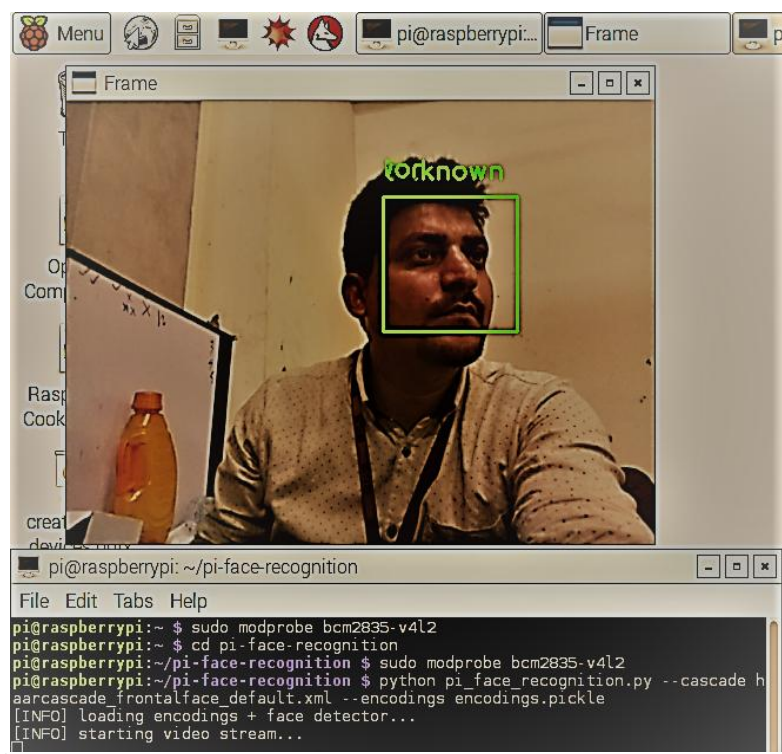

150

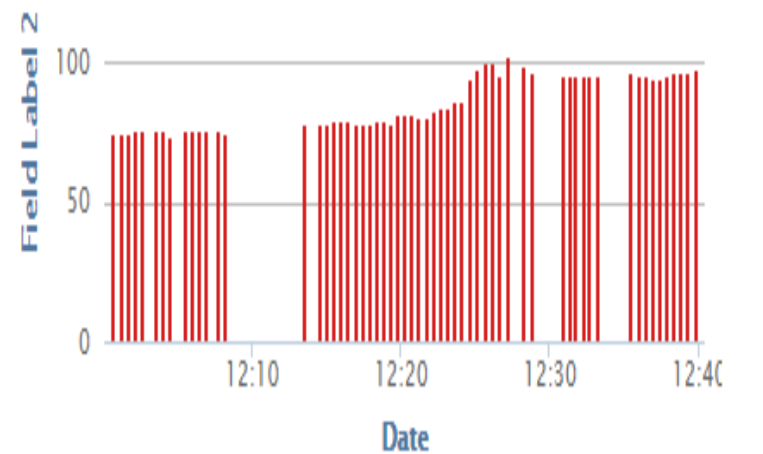

ThingSpeak.com

Fig6. View of the outcome in terms of live video streaming of dustbin Video and graph read by ultrasonic sensor to measure the level in $\mathrm{cm}$.

\section{VI.CONCLUSION AND FUTURE SCOPE}

A unique system that not only helps in the management of trash and trash bins via IoT technology has been proposed and named as SPRUCE. This system will provide a smart solution to the problem in which identification of the person, that is over utilizing the trash bins can also be identified. Camera module can make this system unique of its kind and help to capture the basis for future action and inquiry

\section{REFERENCES}

1. Argulwar, P., Borse, S., Argulwar, K.N. and Gurunathappa, U.S., 2018. IoT-Based Smart Garbage Management System. In International Conference on Intelligent Computing and Applications (pp. 237-245). Springer, Singapore.

2. Narsapur, R., Chowdary, T., Kumar, N. and Manjunath, K.G., 2018. IoT Based Waste Bin Level Management System. Current Trends in Information Technology, 7(3), pp.29-35.

3. Bajaj, A. and Reddy, S., 2017. Garbage Monitoring System Using IOT. International Journal of Pure and Applied Mathematics, 114(12), pp.155-161.

4. Ramesh, Megha, N. HarshitaSubbaiah, B. S. Punyashree, and M. N. Sowjanya. "Solid Waste Management Using IoT." (2018).

5. Deka, K. and Goswami, K., 2018. IoT-Based Monitoring and Smart Planning of Urban Solid Waste Management. In Advances in
Communication, Devices and Networking (pp. 895-905). Springer, Singapore.

6. Gattim NK, Krishna MG, Nadh BR, Madhu N, Reddy CL. IoT-Based Green Environment for Smart Cities. In Microelectronics, Electromagnetics and Telecommunications 2018 (pp. 263-271). Springer, Singapore.

7. Verma, Shiv Prakash. "Web server based 24/7 care management system for better quality of life to Alzheimer, dementia, autistic and assisted living people using artificial intelligent based smart devices." U.S. Patent Application No. 15/971,605.

8. Haribabu, P., Kassa, S.R., Nagaraju, J., Karthik, R., Shirisha, N. and Anila, M., 2017, December. Implementation of a smart waste management system using IoT. In 2017 International Conference on Intelligent Sustainable Systems (ICISS) (pp. 1155-1156). IEEE.

9. Fallavi, K.N., Kumar, V.R. and Chaithra, B.M., 2017, February. Smart waste management using Internet of Things: A survey. In I-SMAC (IoT in Social, Mobile, Analytics and Cloud (I-SMAC), 2017 International Conference on (pp. 60-64). IEEE.

10. Gupta PB, Kumar PR, Anisha BS. Smart Waste Management System. Automation and Autonomous System. 2018;10(5):97-9.

11. Khan, S., Venkat, S. and Jayavel, K., 2017, September. Autonomous smart waste collection system using internet of things. In 2017 IEEE International Conference on Power, Control, Signals and Instrumentation Engineering (ICPCSI) (pp. 1181-1186). IEEE.

12. Bharadwaj, B., M. Kumudha, and G. Chaithra. "Automation of Smart waste management using IoT to support "Swachh Bharat Abhiyan"-a practical approach." In Computing and Communications Technologies (ICCCT), 2017 2nd International Conference on, pp. 318-320. IEEE, 2017.

\section{BIOGRAPHY OF AUTHORS}

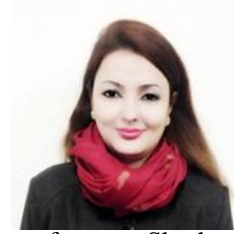

Ms. Navjot Rathour is associated with Lovely Professional University as Assistant Professor with more than 8 years of experience in academics. She is pursuing her $\mathrm{PhD}$ Electronics and communication engineering from Lovely Professional University. She has one patent in her account .She has published Seven research papers in referred journals and conference. She has organized a number of summer internship and expert lectures for students. She has awarded with "Academic Honour" from Lovely Professional University in her Masters for being University Topper.

Dr. Anita Gehlot is associated with Lovely Professional University as

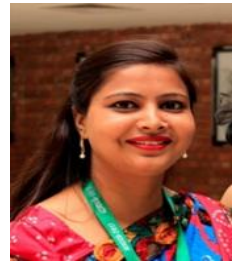
Associate Professor with more than ten years of experience in academics. She has twenty patents in her account. She has published more than fifty research papers in referred journals and conference. She has organized a number of workshops, summer internships and expert lectures for students. She has been awarded with "certificate of appreciation" from University of Petroleum and Energy Studies for exemplary work. She has published fifteen books in the area of Embedded Systems and Internet of Things with reputed publishers like CRC/Taylor \& Francis, Narosa, GBS, IRP, NIPA, River Publishers, Bentham Science and RI publication. She is editor to a special issue published by AISC book series, Springer with title "Intelligent Communication, Control and Devices-2018".

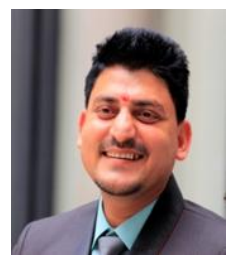

Dr. Rajesh Singh is currently associated with Lovely Professional University as Professor with more than fifteen years of experience in academics. He has been awarded as gold medallist in M.Tech and Hons. in his B.E. His area of expertise includes embedded systems, robotics, wireless sensor networks and Internet of Things. He has organized and conducted a number of workshops, summer internships and expert lectures for students as well as faculty. He has been honoured as keynote speakers and session chair to international/national conferences, faculty development programs and workshops. He has twenty three patents in his account. He has published around hundred research papers in referred journals/conferences.

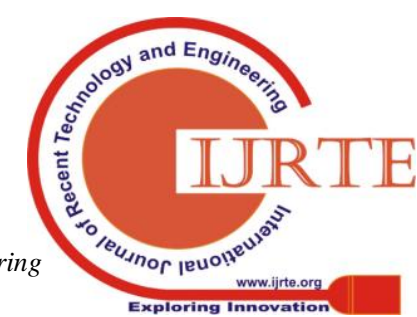

